\title{
Efeito de Doadores de Elétrons na Polimerização de Butadieno com Catalisadores à Base de Neodímio
}

\author{
Tereza C. J. Rocha, Bluma G. Soares \\ IMA, UFRJ \\ Fernanda M. B. Coutinho, Marcos A. S. Costa \\ Instituto de Química, UERJ
}

\begin{abstract}
Resumo: Foi estudado um processo de polimerização de butadieno, em escala de laboratório, para a obtenção de polibutadieno com alto teor de unidades repetitivas 1,4-cis. Foi utilizado um sistema catalítico do tipo Ziegler-Natta ternário, constituído por versatato de neodímio (catalisador), hidreto de diisobutilalumínio (cocatalisador) e cloreto de tert-butila (agente de cloração). O solvente utilizado foi uma mistura de hexano e ciclo-hexano $(80 / 20 \mathrm{v} / \mathrm{v})$. Foi estudado sistematicamente o efeito da presença de dois doadores de elétrons, tetra-hidrofurano (THF) e tetrametiletilenodiamina (TMEDA). Os doadores de elétrons foram adicionados ao meio da polimerização e/ou à solução do preparo do catalisador. A proporção dos compostos doadores de elétrons variou entre 20 e 200 ppm para o THF e entre 0 e 15 ppm para o TMEDA. Observou-se o efeito dos doadores de elétrons sobre a estereosseletividade e a atividade do sistema catalítico, a massa molar e a distribuição de massa molar do polibutadieno obtido. Os polímeros foram caracterizados por espectroscopia na região do infravermelho, cromatografia por exclusão de tamanho e calorimetria diferencial de varredura. Foram obtidos polímeros com teores de unidades 1,4-cis variando entre $99,2 \%$ e $93 \%$. A massa molar ponderal média, $\overline{M w}$, variou de 2,2 a 7,0 x $10^{5}$. A temperatura de transição vítrea dos polímeros se manteve em torno de $-110{ }^{\circ} \mathrm{C}$.
\end{abstract}

Palavras-chave: Polibutadieno alto-cis, catalisador Ziegler-Natta, doadores de elétrons.

\section{Effect of Electron Donors on the Polymerization of Butadiene with Ziegler-Natta Catalysts Based on Neodymium}

Abstract: A laboratory scale process for producing polybutadiene with high content of cis-1,4 repeating units was studied. A Ziegler-Natta catalytic system constituted of neodymium versatate (catalyst), diisobutylaluminium hydride (cocatalyst) and tert-butyl chloride (chlorinating agent) was used. The solvent employed was a mixture of hexane and cyclohexane $(80 / 20 \mathrm{v} / \mathrm{v})$. The effect of two electron donors, tetrahydrofuran (THF) and tetramethylethylenediamine (TMEDA), was studied. The electron donors were added to the polymerization medium and/or to the solvent employed in the catalyst preparation. The proportion of electron donors was varied between 20 and $200 \mathrm{ppm}$ for THF and between 0 and $15 \mathrm{ppm}$ for TMEDA. The influence of electron donors on the stereoselectivity, catalytic activity, molar mass and molar mass distribution of polybutadiene was evaluated. The polymers were characterized by infrared spectroscopy, size exclusion chromatography and differential scanning calorimetry. Polymers with cis-1,4 units content varying between $99.2 \%$ and $93 \%$ were produced. The weight-average molar mass, $\bar{M} w$, varied from 2.2 to $7.0 \times 10^{5}$. The polymers glass transition temperature was kept around $-110^{\circ} \mathrm{C}$.

Keywords: High cis-1,4 polybutadiene, Ziegler-Natta catalyst, electron donors.

\section{Introdução}

Das borrachas sintéticas consumidas mundialmente, o polibutadieno (BR) tem consumo anual aproximado de 2 milhões de toneladas, atrás somente do elastômero estirenobutadieno (SBR). Seu maior mercado consumidor é a indústria de pneus, responsável pelo consumo de 67 a 70\% da produção mundial ${ }^{[1]}$.

Os fabricantes de pneumáticos e de bandas de rodagem têm desenvolvido novos produtos para atender às mudanças ocorridas na indústria automobilística. Essas mudanças estão relacionadas às questões ambientais sobre o aquecimento global e à redução de emissão de gases poluentes na atmosfera. Por ser o único meio de contato entre o veículo e o solo, os pneus representam um importante item de desenvolvimento para a diminuição de forças de atrito visando a redução do consumo de combustível ${ }^{[2]} \mathrm{e}$ conseqüentemente das emissões gasosas.

O polibutadieno com alto teor de unidades repetitivas 1,4-cis exibe excelentes propriedades para sua aplicação na

Autor para correspondência: Fernanda M. B. Coutinho, Departamento de Processos Químicos, Instituto de Química, UERJ, Av. São Francisco Xavier 524 Maracanã, Pavilhão Haroldo Lisboa da Cunha, CEP: 20559-900, Rio de Janeiro, RJ. E-mail: fern@uerj.br 
produção de pneus, pois apresenta boa resistência à abrasão, boa resistência à fadiga, boa resistência ao rasgo, baixa resistência ao rolamento e baixo desenvolvimento de calor ${ }^{[3]}$.

O polibutadieno alto-cis é produzido por polimerização em solução em presença de catalisadores estereoespecíficos do tipo Ziegler-Natta. Os sistemas catalíticos utilizados determinam a estrutura química e estereoquímica dos polímeros produzidos e conseqüentemente as suas propriedades. As tecnologias comercialmente desenvolvidas para a produção de polibutadieno alto-cis utilizam catalisadores à base de titânio, níquel, cobalto e neodímio, sendo este último o de tecnologia mais recente e o que fornece polímeros com o mais alto teor de unidades 1,4-cis $(98 \%)^{[4]}$.

Diversos estudos vêm sendo desenvolvidos ao longo dos últimos anos sobre a polimerização de butadieno com catalisadores à base de $\mathrm{Nd}$. A maioria desses estudos trata do efeito do tipo de composto de neodímio, da variação da razão molar entre os componentes do catalisador, do tipo de cocatalisador e da temperatura de polimerização sobre a conversão do monômero e sobre o teor de unidades 1,4-cis dos polímeros produzidos ${ }^{[5]}$.

Poucos estudos ${ }^{[6]}$ abordaram o efeito da presença de compostos doadores de elétrons no meio reacional da polimerização ou na solução do preparo do catalisador. O presente estudo foi desenvolvido com o objetivo de se determinar o efeito da contaminação do solvente, utilizado em escala industrial na produção do PB alto-cis, por compostos doadores de elétrons. Essa possibilidade de contaminação, com compostos doadores de elétrons, deve-se ao fato de o solvente utilizado poder ter sido recuperado de um processo de polimerização aniônica, onde esses doadores são propositalmente adicionados.

Assim, este trabalho teve como objetivo estudar o efeito de dois doadores de elétrons, tetra-hidrofurano (THF) e tetrametiletilenodiamina (TMEDA), sobre a polimerização de butadieno com o sistema catalítico constituído por versatato de neodímio, hidreto de diisobutilalumínio (DIBAH) e cloreto de tert-butila.

\section{Experimental}

\section{Materiais}

Hidreto de diisobutialuminio (DIBAH) fornecido pela Akzo Nobel e utilizado como recebido.

Versatato de neodímio, doado pela Petroflex S.A, procedência: Rhodia Rare-Earths and Gallium, utilizado como recebido.

Cloreto de t-butila, fornecido pela Aldrich Chemical Company, Inc.; grau de pureza: $99 \%$, usado como recebido.

Hexano, fornecido pela Vetec Química Fina Ltda, grau de pureza: P.A; usado após refluxo sobre fitas de sódio seguido de destilação.

Ciclo-hexano, fornecido pela Isofar Indústria e Comércio de Produtos Químicos Ltda; grau de pureza: P.A; usado após refluxo sobre fitas de sódio seguido de destilação.

3-5-Di-tert-butil-4-hidroxitolueno (BHT), procedência: Shell Química, usado como recebido.
Irganox 1076, procedência: Ciba Geigy Química S/A, usado como recebido.

Fosfito de trinonilfenila (TNPP), procedência: GE Specialty Chemicals, usado como recebido.

Blend B (solução de butadieno em hexano), doado pela Petroflex S.A, usado como recebido.

Tetra-hidrofurano (THF), procedência: Vetec Química Fina Ltda; grau de pureza: P.A; usado após refluxo sobre fitas de sódio seguido de destilação.

Tetrametiletilenodiamina (TMEDA), procedência: Vetec Química Fina Ltda; grau de pureza: P.A, usado como recebido.

Nitrogênio comercial, procedência: White Martins S.A, purificado por passagem através de coluna recheada com peneira molecular de $3 \AA \AA$ e de coluna com pentóxido de fósforo.

Nitrogênio super-seco, procedência: White Martins S.A, grau de pureza: 99,995\%; passado através de coluna recheada com peneira molecular de $3 \AA$.

\section{Tratamento da vidraria}

Toda a vidraria utilizada no tratamento do solvente, no preparo das soluções, na síntese do catalisador e na polimerização do butadieno foi tratada com potassa alcoólica, solução de ácido clorídrico a 5\%, lavada com água destilada e seca em estufa a $125^{\circ} \mathrm{C}$ por, pelo menos, 12 horas. Todos os sistemas de vidro relacionados com o tratamento do solvente, síntese do catalisador e preparo de soluções foram montados a quente e resfriados sob fluxo de nitrogênio seco.

\section{Tratamento dos solventes}

Os solventes, hexano e ciclo-hexano, foram secos e destilados. Ambos foram, separadamente, refluxados sobre sódio, em atmosfera inerte, por um período de 4 horas e destilados a pressão atmosférica, sob fluxo de nitrogênio. Os destilados foram recolhidos em frasco contendo peneira molecular.

\section{Tratamento do THF}

O doador de elétrons, THF, foi refluxado sobre fitas de sódio, em atmosfera inerte, por um período de 4 horas e destilado à pressão atmosférica, sob fluxo de nitrogênio. $\mathrm{O}$ destilado foi recolhido em frasco contendo peneira molecular.

\section{Preparo das soluções de hidreto de diisobutilalumínio e cloreto de t-butila}

As soluções foram preparadas em Schlenk, previamente seco em estufa a $125^{\circ} \mathrm{C}$ por 24 horas e resfriado sob fluxo de $\mathrm{N}_{2}$. Para a solução de hidreto de diisobutilalumínio, adicionou-se ao solvente (hexano) volume determinado do alquilalumínio sob fluxo de nitrogênio. O mesmo procedimento foi adotado para o preparo da solução de cloreto de tert-butila. Essas soluções foram utilizadas imediatamente após o seu preparo.

\section{Preparo do catalisador}

O catalisador foi sintetizado em garrafa de vidro com capacidade de $300 \mathrm{ml}$, previamente seca em estufa a $125^{\circ} \mathrm{C}$, por 
aproximadamente 12 horas. Imediatamente após a retirada da garrafa da estufa, colocou-se em seu interior uma barra magnética revestida de teflon e, logo em seguida, lacrou-se a mesma com gaxeta de borracha e tampa de alumínio, sendo então o sistema resfriado sob nitrogênio seco.

A garrafa, após atingir a temperatura ambiente, foi colocada sobre placa de agitação magnética. Adicionou-se então volume determinado de uma solução de DIBAH em hexano. O sistema foi mantido entre 5 e $10^{\circ} \mathrm{C}$, em banho termostatizado e deixado sob agitação. Após 10 minutos, foi adicionada lentamente uma solução de concentração conhecida de versatato de neodímio em hexano e o sistema foi mantido por mais 10 minutos sob agitação, na mesma faixa de temperatura. Novamente, após 10 minutos, adicionou-se volume determinado de uma solução de cloreto de t-butila em hexano, de concentração conhecida. A solução resultante foi mantida sob agitação, por 1 hora, na faixa de temperatura citada anteriormente. Em seguida, o catalisador foi levado para câmarafria, cuja temperatura é de aproximadamente $5^{\circ} \mathrm{C}$ e deixado em repouso para envelhecimento por 24 horas. A razão molar entre os componentes do sistema catalítico foi fixada em $\mathrm{Al}: \mathrm{Nd}: \mathrm{Cl} .=11: 1: 3$.

O mesmo procedimento, utilizado na preparação do catalisador padrão, foi empregado para o preparo do catalisador com doador de elétrons. A única diferença foi a adição de quantidade determinada de doador de elétrons ao solvente (hexano/ciclo-hexano) de preparo das soluções de DIBAH e cloreto de tert-butila.

\section{Polimerização de 1,3-butadieno}

Em um reator de $1 \mathrm{~L}$ de capacidade, provido de agitação mecânica e sistema de aquecimento, foi adicionado volume determinado de solução de butadieno em hexano (Blend B), a cerca de $70{ }^{\circ} \mathrm{C}$. Em seguida, adicionou-se a metade do volume necessário de solvente (hexano, ciclo-hexano ou suas misturas). Sob atmosfera de nitrogênio, adicionou-se um volume determinado da solução de catalisador à base de neodímio em vaso adequado, para posterior transferência para o reator. A temperatura foi mantida em $70^{\circ} \mathrm{C}$. Após duas horas de reação, o polímero formado foi transferido para um reator de vidro contendo solvente, previamente inertizado, onde foi realizada a terminação da reação de polimerização. Após a transferência completa do polímero, adicionou-se volume determinado de uma solução de concentração conhecida de BHT em hexano. A mistura foi deixada sob agitação por 15 minutos. Em seguida, foi adicionado volume determinado de uma solução de concentração conhecida de antioxidante Irganox/TNPP em hexano. A mistura foi então deixada sob agitação por mais 15 minutos. O polímero foi finalmente coagulado em um reator de vidro encamisado contendo água desmineralizada a cerca de $85^{\circ} \mathrm{C}$, sob agitação mecânica vigorosa (500 rpm ), e deixado nessas condições por cerca de 2 horas. O polímero obtido foi seco a $65^{\circ} \mathrm{C}$ em estufa, durante 24 horas.

O mesmo procedimento, utilizado para promover a reação de polimerização sem doadores de elétrons, foi empregado para promover a reação de polimerização com adição de doa- dor de elétrons ao solvente da polimerização. A única diferença foi a adição de quantidade determinada de doador de elétrons ao vaso do solvente de polimerização, antes de sua transferência para o reator.

\section{Caracterização}

A determinação das massas molares médias e da polidispersão foi feita por cromatografia de exclusão por tamanho (SEC), utilizando o cromatógrafo de permeação em gel (GPC) Waters 600, equipado com injetor automático Waters 717 Autosampler, detector de índice de refração 2410 e colunas de Styragel com limites de exclusão entre 50 e 1x10 $\AA$, calibradas com padrões monodispersos de poliestireno. As medidas foram executadas a $30{ }^{\circ} \mathrm{C}$ e as amostras injetadas automaticamente como solução a $0,15 \%(\mathrm{p} / \mathrm{v})$ em THF.

A microestrutura foi determinada por espectroscopia na região do infravermelho. As amostra de polibutadieno foram preparadas na forma de filme vazado sobre célula de $\mathrm{KBr}$, a partir de solução a $2 \%$ (peso/volume) em clorofórmio. Os espectros foram obtidos na faixa espectral de 4000 a $200 \mathrm{~cm}^{-1}$. Os teores de unidades repetitivas, 1,4-trans, 1,2-vinila e 1,4cis foram obtidos segundo método de Schröeder, a partir das absorbâncias correspondentes aos números de onda a 967, 910 e $740 \mathrm{~cm}^{-1}$, respectivamente.

A temperatura de transição vítrea ( $\mathrm{Tg}$ ) foi determinada por calorimetria diferencial de varredura (DSC), usando um calorímetro diferencial de varredura da TA Instruments, modelo MDSC 2920. A Tg foi estimada no ponto de inflexão na curva de DSC . A análise foi conduzida em atmosfera de nitrogênio, sob uma velocidade de aquecimento de $5{ }^{\circ} \mathrm{C} / \mathrm{min}$, de -140 to $30^{\circ} \mathrm{C}$.

\section{Resultados e Discussão}

Os primeiros estudos envolvendo o uso de doadores de elétrons nos catalisadores à base de complexos de coordenação na polimerização do 1,3-butadieno foram relatados, no período de 1956 a 1958, em algumas patentes. Os doadores de elétrons utilizados nesses estudos eram compostos polares, tais como, aminas e éteres que tinham como objetivo diminuir o teor de gel da polimerização e aumentar a estereoespecificidade do catalisador. No entanto, esses estudos foram essencialmente empíricos, pois os pesquisadores não tinham a menor idéia da forma como esses doadores de elétrons operavam. A partir de 1960, outros estudos puderam, gradualmente, esclarecer melhor, o papel desses doadores de elétrons, quando utilizados em catalisadores à base de complexos de coordenação. Uma das primeiras observações, foi que o teor de unidades 1,4-cis do polibutadieno diminuía até um valor limite, com o aumento da concentração de doadores de elétrons. Bases de Lewis, tais como éteres e aminas, adicionadas ao sistema catalítico $\mathrm{AlH}_{3} /$ $\mathrm{TiCl}_{4}$, para polimerizar 1,3-butadieno, produziam um pequeno efeito quando em baixas concentrações. Contudo, em quantidades maiores, provocavam uma redução acentuada no teor de unidades 1,4-cis do polibutadieno e na velocidade de polimerização ${ }^{[7]}$. 
Tabela 1. Características dos polibutadienos obtidos com adição de THF ao solvente da polimerização

\begin{tabular}{|c|c|c|c|c|c|c|c|}
\hline \multirow{2}{*}{$\begin{array}{c}\text { Polimerização } \\
\text { THF (ppm) }\end{array}$} & \multirow{2}{*}{$\begin{array}{c}\text { Massa de } \\
\text { PB }(\mathrm{g})\end{array}$} & \multicolumn{3}{|c|}{ Microestrutura (\%) } & \multicolumn{2}{|c|}{ PM $\times 10^{-4}$} & \multirow{2}{*}{$\overline{\mathbf{M}} \mathbf{w} / \overline{\mathbf{M}} \mathbf{n}$} \\
\hline & & 1,4-cis & 1,4-trans & 1,2-vinila & $\overline{\mathbf{M}} \mathbf{n}$ & $\overline{\mathbf{M}} \mathbf{w}$ & \\
\hline Sem doador de elétrons & 26 & 99,2 & 0,3 & 0,5 & 27,0 & 72,1 & 2,7 \\
\hline 20 & 21 & 96,7 & 2,6 & 0,6 & 10,2 & 32,4 & 3,2 \\
\hline 30 & 20 & 96,5 & 2,9 & 0,6 & 10,6 & 37,8 & 3,6 \\
\hline 40 & 19 & 96,4 & 2,9 & 0,6 & 8,4 & 25,5 & 3,1 \\
\hline 100 & 18 & 96,4 & 2,9 & 0,6 & 6,5 & 28,4 & 4,4 \\
\hline 150 & 18 & 96,2 & 3,2 & 0,6 & 6,4 & 28,9 & 4,5 \\
\hline 200 & 17 & 95,3 & 4,0 & 0,6 & 5,9 & 29,6 & 5,0 \\
\hline
\end{tabular}

Condições reacionais: Solvente: 80/20 (\%v/v) - hexano/ciclo-hexano; temperatura de reação: $70{ }^{\circ} \mathrm{C}$; razão molar Al/Nd: $11 ;$ razão molar Cl/Nd: 3,0; $0,25 \mathrm{mmol}$ de $\mathrm{Nd} / 100 \mathrm{~g} \mathrm{Bd}$; $\mathrm{PB}=$ polibutadieno

Atualmente, os catalisadores Ziegler-Natta são bastante utilizados para promover a polimerização do butadieno com alto teor de unidades 1,4-cis e entre esses estão os sistemas catalíticos à base de lantanídeos ${ }^{[8]}$. Os sistemas catalíticos binários à base desses metais utilizam normalmente, um cloreto do lantanídeo $\left(\mathrm{NdCl}_{3}\right)$, um doador de elétrons (THF) e um alquilalumínio ( $\mathrm{AlEt}_{3}$ ), produzindo polibutadienos com $97 \%$ de unidades 1,4-cis e com $100 \%$ de conversão. Esses sistemas utilizam THF, solvente muito útil para diversas sínteses organometálicas, que não reage com o alquilalumínio, a não ser para formar um complexo ácido-base (de Lewis) ${ }^{[9]}$. Os sistemas ternários à base de neodímio são os que produzem os mais altos teores de unidades 1,4-cis (\%99), altos valores de massa molar e baixa polidispersão no polibutadieno. Os sistemas ternários são constituídos por um composto de neodímio, um alquilalumínio e um agente de cloração. Nesse tipo de sistema catalítico, não é necessário a adição de um doador de elétrons. Esses sistemas vêm sendo muito utilizados pelas indústrias produtoras de polibutadieno alto-cis ${ }^{[10]}$.

Assim, este trabalho teve o objetivo de determinar os efeitos de compostos doadores de elétrons (um éter e uma amina), quando presentes no solvente de polimerização do 1,3-butadieno e quando adicionados ao solvente do sistema catalítico ternário à base de neodímio. Os doadores de elétrons utilizados foram THF e TMEDA, em diferentes proporções. Primeiramente, esses compostos foram adicionados apenas ao solvente da polimerização e após a observação do efeito que este causava às propriedades do polímero, selecionou-se um teor para contaminar o solvente do catalisador. Finalmente, o solvente do catalisador e o solvente da polimerização foram simultaneamente contaminados.

O primeiro doador de elétrons testado foi o THF, que foi adicionado em diferentes teores apenas ao solvente da polimerização (Tabela 1).

Os resultados de rendimento demonstram que, quando se adicionou o doador de elétrons ao solvente da polimerização, ocorreu inicialmente um decréscimo na massa do polímero obtido (26 g para $21 \mathrm{~g}$ ). No entanto, esses valores de massa para os polibutadienos não sofreram uma variação acentuada à medida que se aumentou o teor de THF no solvente da polimerização. Sendo estes valores de rendimento muito próximos (21 g, 20 g, 19 g, 18 g, 17 g), resolveu-se contaminar o solvente de preparo do catalisador com 200 ppm de THF, a fim de verificar se a variação nas massas não foi ocasionada pelas perdas de massa polimérica durante o processo de coagulação e secagem. Assim, decidiu-se testar o efeito da adição de 200 ppm de THF, pois deste modo poder-se-ia avaliar o início do efeito deletério desse doador de elétrons.

A microestrutura do polibutadieno sofreu uma variação acentuada com a adição de 20 ppm de THF, contudo, manteve-se praticamente constante a partir de $30 \mathrm{ppm}$ de THF. O teor de unidades 1,4-cis se manteve em torno de 96,4\%, sofrendo uma nova queda quando se adicionou $200 \mathrm{ppm}$ de THF. O teor de unidades 1,4-trans aumentou acentuadamente (de 0,3 para $4,0 \%$ ) e o teor de unidades vinílicas sofreu apenas um ligeiro aumento ( de 0,5 para $0,6 \%$ ).

A variação na microestrutura do polibutadieno provocada pela presença do THF (doador de elétrons) no meio reacional ${ }^{[11]}$ pode ser explicada. Segundo Porri ${ }^{[12]}$, doadores de elétrons, tais como aminas e éteres, são capazes de ocupar uma das vacâncias do metal de transição, disponível para a coordenação com o monômero, fazendo com que a nova molécula de monômero se coordene com apenas uma dupla ligação, o que resulta no decréscimo do teor de unidades 1,4-cis e aumento do teor de unidades 1,4-trans.

A massa molar numérica média variou na faixa de $5,9 \mathrm{x}$ $10^{4}$ a $27,0 \times 10^{4}$ e a polidispersão aumentou, evidenciando a ocorrência de reações de transferência de cadeia. A massa molar ponderal médio também sofreu um decréscimo acentuado, ao se comparar o valor obtido para o polímero sem adição de THF com os valores apresentados para os polímeros obtidos em presença de THF. A distribuição de massa molar aumentou acentuadamente à medida que se aumentou o teor de THF no meio reacional. Isso se deve à ocorrência de reações de transferência de cadeia, conforme já mencionado.

Dando continuidade ao estudo, adicionou-se $200 \mathrm{ppm}$ de THF ao solvente do catalisador e, simultaneamente, ao solvente do meio da polimerização e do catalisador (Tabela 2), afim de verificar se o efeito deletério do THF sobre as características do polímero era mais acentuado, quando presente no solvente catalisador. 
Tabela 2. Características dos polibutadienos obtidos com adição de THF apenas ao solvente do catalisador

\begin{tabular}{|c|c|c|c|c|c|c|c|}
\hline \multirow{2}{*}{ Polimerização } & \multirow{2}{*}{$\begin{array}{l}\text { Massa de } \\
\text { PB (g) }\end{array}$} & \multicolumn{3}{|c|}{ Microestrutura (\%) } & \multicolumn{2}{|c|}{ PM $\times 10^{-4}$} & \multirow{2}{*}{$\overline{\mathbf{M}} \mathbf{w} / \overline{\mathbf{M}} \mathbf{n}$} \\
\hline & & 1,4-cis & 1,4-trans & 1,2-vinila & $\overline{\mathbf{M}} \mathbf{n}$ & $\overline{\mathbf{M}} \mathbf{w}$ & \\
\hline Sem doador de elétrons & 26 & 98,4 & 0,3 & 0,5 & 23,8 & 60,3 & 2,5 \\
\hline $\begin{array}{l}200 \mathrm{ppm} \text { de THF no } \\
\text { solvente do catalisador }\end{array}$ & 17 & 94,3 & 4,7 & 0,6 & 3,0 & 23,0 & 7,7 \\
\hline $\begin{array}{l}200 \text { ppm de THF no } \\
\text { solvente do catalisador e no } \\
\text { solvente da polimerização }\end{array}$ & 12 & 93,2 & 6,1 & 0,8 & 2,5 & 30,9 & 12,5 \\
\hline
\end{tabular}

Condições reacionais: Solvente: 80/20 (\%v/v) - hexano/ciclo-hexano; temperatura de reação: $70{ }^{\circ} \mathrm{C}$; razão molar $\mathrm{Al} / \mathrm{Nd}$ : $11 ;$ razão molar $\mathrm{Cl} / \mathrm{Nd}$ : 3,0; $0,25 \mathrm{mmol}$ de $\mathrm{Nd} / 100 \mathrm{~g} \mathrm{Bd} ; \mathrm{PB}=$ polibutadieno

Quando foram adicionados $200 \mathrm{ppm}$ de THF ao solvente de preparo do catalisador, como era de se esperar, a massa do polímero diminuiu. Contudo, quando 200 ppm de THF foram adicionados ao solvente do catalisador e ao solvente da polimerização, o decréscimo no rendimento do polímero, como era de esperar, foi ainda mais acentuado. Esse resultado demonstra que, se o solvente utilizado na produção de polibutadieno alto-cis for proveniente de um solvente recuperado de um processo de polimerização aniônica (contaminado com THF), resultará na queda do rendimento do polímero para pelo menos a metade, se o teor de THF estiver em torno de $200 \mathrm{ppm}$.

Analisando a microestrutura do polibutadieno, observou-se que o teor de unidades 1,4-cis caiu acentuadamente, o de unidades 1,4-trans aumentou e o teor de unidades 1,2-vinila sofreu apenas um ligeiro aumento, quando o THF foi adicionado ao solvente do catalisador (Tabela 2). Isso pode ser atribuído ao fato de que, quando o THF é adicionado ao solvente do catalisador, este atua diretamente sobre o catalisador e naturalmente, sobre os sítios catalíticos. À medida que o sítio catalítico é formado, o THF (base de Lewis) se coordena com o neodímio, diminuindo a estereoespecificidade do catalisador, pois obriga o monômero a se coordenar com apenas uma dupla ligação ${ }^{[12]}$.

A massa molar diminuiu e a distribuição de massa molar aumentou acentuadamente (Tabela 2). Esses resultados demonstram que a presença do THF no meio da polimerização, favorece as reações de transferência de cadeia, diminuindo a massa molar e aumentando a polidispersão ( $\overline{\mathrm{M}} \mathrm{w} / \overline{\mathrm{M}} \mathrm{n})$. O efeito dos doadores de elétrons sobre as características do polímero foi mais acentuado quando estes foram adicionados ao solvente do preparo do catalisador, do que quando adicionados apenas ao solvente da polimerização.
Foi feito um segundo estudo utilizando como doador de elétrons uma amina, tetrametiletilenodiamina (TMEDA), para verificar o efeito que esta base de Lewis poderia causar à polimerização de 1,3-butadieno. A Tabela 3 apresenta o rendimento das reações realizadas adicionando-se TMEDA apenas ao solvente da polimerização e as características dos polímeros produzidos.

O rendimento da polimerização caiu acentuadamente com o aumento do teor de TMEDA. Como já mencionado anteriormente, doadores de elétrons, tais como aminas, quando presentes em alto teor, podem competir com o monômero pela coordenação com o metal de transição, diminuindo a atividade e a estereoespecificidade catalíticas ${ }^{[7]}$.

Os valores encontrados para o teor de unidades 1,4-cis, em torno de 98,5\%, mantiveram-se praticamente constantes até a adição de 5 ppm de TMEDA. Quando foram adicionados 15 ppm de TMEDA, ocorreu uma queda acentuada no teor de unidades 1,4-cis do polímero. O teor de unidades 1,4-trans aumentou gradualmente à medida que foram adicionados teores crescentes de TMEDA no solvente da polimerização. Entretanto, o teor de unidades 1,2-vinila, manteve-se praticamente constante, em torno de $0,60 \%$, quando se aumentou o teor de TMEDA no meio da polimerização até $5 \mathrm{ppm}$ e mostrou um aumento significativo quando foram adicionados 15 ppm de TMEDA.

Há estudos na literatura ${ }^{[7]}$ sobre a influência de doadores de elétrons na polimerização de butadieno, com sistemas catalíticos à base de cobalto. Quando o doador de elétrons utilizado era uma amina terciária, o mecanismo proposto para mostrar a aproximação da amina ao metal de transição (cobalto) é mostrado na Figura 1.

Tabela 3. Características dos polibutadienos obtidos com adição de TMEDA ao solvente da polimerização

\begin{tabular}{|c|c|c|c|c|c|c|c|}
\hline Polimerização & \multirow{2}{*}{$\begin{array}{c}\text { Massa de } \\
\text { PB (g) }\end{array}$} & \multicolumn{3}{|c|}{ Microestrutura (\%) } & \multicolumn{2}{|c|}{ PM x $10^{-4}$} & \multirow{2}{*}{$\overline{\mathbf{M}} \mathbf{w} / \overline{\mathbf{M}} \mathbf{n}$} \\
\hline TMEDA (ppm) & & 1,4-cis & 1,4-trans & 1,2-vinila & $\overline{\mathbf{M}} \mathbf{n}$ & $\overline{\mathbf{M}} \mathbf{w}$ & \\
\hline Sem doador de elétrons & 25 & 98,7 & 0,6 & 0,6 & 22,4 & 61,8 & 2,7 \\
\hline 1 & 20 & 98,4 & 1,0 & 0,6 & 18,4 & 57,1 & 3,1 \\
\hline 5 & 13 & 98,2 & 1,2 & 0,7 & 7,2 & 34,4 & 4,7 \\
\hline 15 & 5 & 95,8 & 3,1 & 1,1 & 5,7 & 29,5 & 5,1 \\
\hline
\end{tabular}

Condições reacionais: Solvente: 80/20 (\%v/v) - hexano/ciclo-hexano; temperatura de reação: $70{ }^{\circ} \mathrm{C}$; razão molar Al/Nd: $11 ;$ razão molar Cl/Nd: 3,0; $0,25 \mathrm{mmol}$ de $\mathrm{Nd} / 100 \mathrm{~g} \mathrm{Bd} ; \mathrm{PB}=$ polibutadieno 


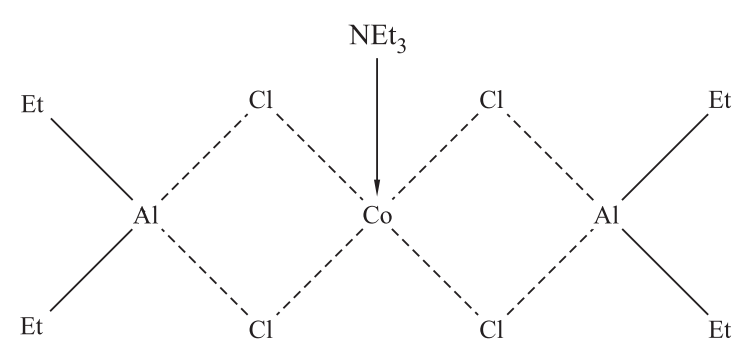

Figura 1. Aproximação da amina de uma das vacâncias do metal de transição ${ }^{[7]}$.

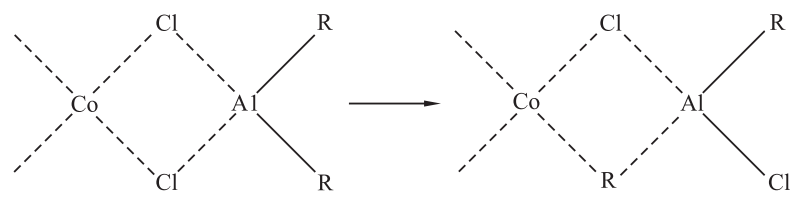

Figura 2. Espécie intermediária do complexo à base de cobalto ${ }^{[7]}$

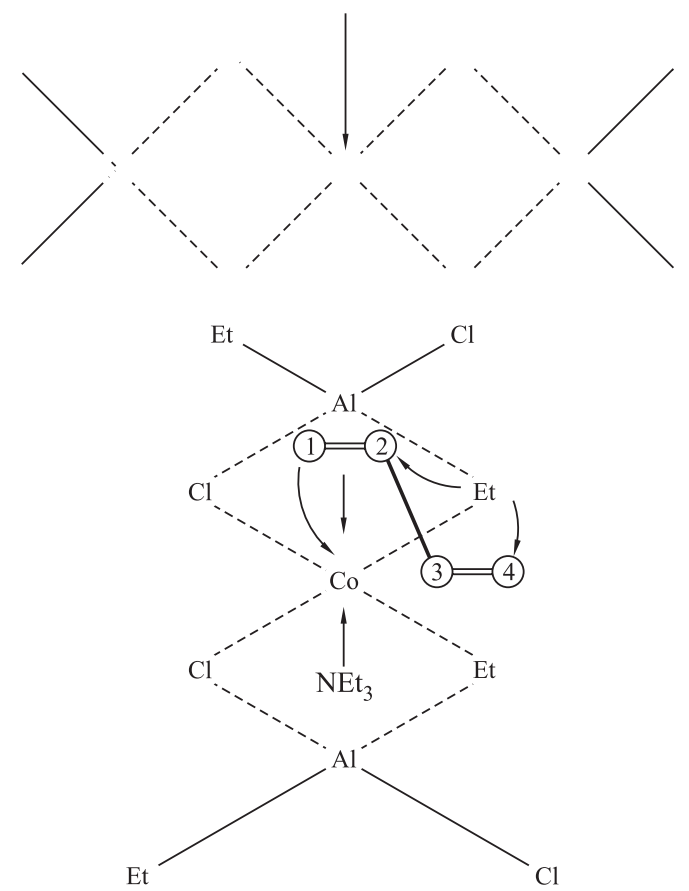

Figura 3. Coordenação do butadieno com uma vacância do metal de transição ${ }^{[7]}$.
Na Figura 2 é representada uma espécie intermediária do complexo à base de cobalto, onde um grupo alquila proveniente do cocatalisador participa da ponte entre o cobalto e o alumínio. Segundo Cooper e colaboradores ${ }^{[7]}$, a inserção da molécula do butadieno ocorre entre a ligação Co-Et com a formação de uma unidade terminal alílica.

A amina obstrui um ponto de coordenação, impedindo que o dieno se coordene com as duas duplas ligações, diminuindo assim o teor de unidades $1,4-$ cis $^{[7]}$. A Figura 3 representa a coordenação do butadieno com o sistema catalítico à base de cobalto. Pode-se observar que a amina ocupa uma vacância do cobalto, impedindo que a dupla ligação localizada entre o carbono 3 e 4 se coordene com o cobalto.

A Tabela 3 mostra que o massa molar diminuiu e a distribuição de massa molar aumentou, à medida que se aumentou o teor de TMEDA no solvente da polimerização.

Observando os resultados das reações em que se adicionou TMEDA ao solvente da polimerização, selecionou-se um teor de TMEDA para contaminar o solvente do catalisador (1 ppm). No estudo seguinte, foram adicionados $1 \mathrm{ppm}$ de TMEDA ao solvente do catalisador e $1 \mathrm{ppm}$ de TMEDA ao solvente da polimerização, os resultados obtidos estão resumidos na Tabela 4.

Os valores do rendimento mostram um decréscimo gradual na massa do polímero. Ao se comparar a polimerização em ausência de doador de elétrons, com a polimerização onde o solvente da polimerização e o solvente do catalisador foram ambos contaminados com 1 ppm de TMEDA (Tabela 4), observa-se nitidamente a queda no rendimento.

$\mathrm{O}$ teor de unidades 1,4-cis sofreu um pequeno decréscimo, o teor de unidades 1,4-trans aumentou e o teor de unidades 1,2-vinila manteve-se praticamente constante, conforme se aumentou o teor de TMEDA (Tabela 4).

A massa molar do polibutadieno decresceu acentuadamente com a adição de TMEDA. Ao se comparar com o polímero obtido em ausência de TMEDA, a distribuição de massa molar apresentou apenas um ligeiro aumento, de 2,7 para 3,5 (Tabela 4).

Os valores encontrados para as características dos polímeros obtidos, quando foi feita a contaminação do solvente do catalisador e do solvente do meio da polimerização com 1 ppm de TMEDA, mostraram que se o solvente utilizado no preparo do catalisador for proveniente de um solvente recuperado de

Tabela 4. Características dos polibutadienos obtidos com adição de TMEDA ao solvente do catalisador e simultaneamente ao solvente do catalisador e ao solvente da polimerização

\begin{tabular}{|c|c|c|c|c|c|c|c|}
\hline Polimerização & \multirow{2}{*}{$\begin{array}{l}\text { Massa de } \\
\text { PB (g) }\end{array}$} & \multicolumn{3}{|c|}{ Microestrutura (\%) } & \multicolumn{2}{|c|}{ PM $\times 10^{-4}$} & \multirow{2}{*}{$\overline{\mathbf{M}} \mathbf{w} / \overline{\mathbf{M}} \mathbf{n}$} \\
\hline THF (ppm) & & 1,4-cis & 1,4-trans & 1,2-vinila & $\overline{\mathbf{M}} \mathbf{n}$ & $\overline{\mathbf{M}} \mathbf{w}$ & \\
\hline Sem doador de elétrons & 25 & 98,7 & 0,6 & 0,6 & 22,4 & 61,8 & 2,7 \\
\hline $\begin{array}{l}1 \mathrm{ppm} \text { de TMEDA no } \\
\text { solvente do catalisador }\end{array}$ & 21 & 97,9 & 1,5 & 0,6 & 7,5 & 26,5 & 3,5 \\
\hline $\begin{array}{l}1 \mathrm{ppm} \text { de TMEDA no } \\
\text { solvente do catalisador e no } \\
\text { solvente da polimerização }\end{array}$ & 18 & 97,4 & 2,0 & 0,7 & 7,2 & 25,1 & 3,5 \\
\hline
\end{tabular}

Condições reacionais: Solvente: 80/20 (\%v/v) - hexano/ciclo-hexano; temperatura de reação: $70^{\circ} \mathrm{C}$; razão molar Al/Nd: $11 ;$ razão molar Cl/Nd: 3,0; $0,25 \mathrm{mmol}$ de $\mathrm{Nd} / 100 \mathrm{~g} \mathrm{Bd}$ 
um processo de polimerização aniônica, esse solvente deve conter menos de 1 ppm de TMEDA. Pois, caso contrário, a massa molar do polímero cairá consideravelmente.

Embora tenham sido mantidas as mesmas condições de polimerização, observou-se que o efeito dos doadores de elétrons sobre as características do polímero foi mais acentuado quando estes eram adicionados ao solvente do preparo do catalisador, do que quando adicionados apenas ao solvente da polimerização. Ocorreu uma queda mais acentuada na massa molar do polímero, quando se adicionou $1 \mathrm{ppm}$ de TMEDA diretamente ao solvente do preparo do catalisador $\left(7,50 \times 10^{4}\right)$, em comparação com o valor da massa molar do polímero obtido com adição de $1 \mathrm{ppm}$ de TMEDA ao solvente da polimerização $\left(1,84 \times 10^{5}\right)$. Isso pode ser atribuído ao fato de que, o TMEDA quando é adicionado ao solvente do catalisador, atua diretamente sobre os sítios catalíticos. Assim, à medida que os sítios catalíticos são formados, o TMEDA se coordena com o neodímio, diminuindo a disponibilidade dos sítios catalíticos para a coordenação com o butadieno, promovendo um maior número de reações de transferência de cadeia e, conseqüentemente, aumentando a distribuição de massa molar, à medida que se aumenta o teor de TMEDA.

A temperatura de transição vítrea, $\mathrm{Tg}$, dos polibutadienos produzidos não foi afetada pela presença de doadores de elétrons, os valores mantiveram-se constantes, em torno de $-110^{\circ} \mathrm{C} \pm 2{ }^{\circ} \mathrm{C}$, esse comportamento é o esperado. Normalmente, só se verifica uma variação significativa na $\mathrm{Tg}$ do polímero, quando ocorre um aumento acentuado no teor de unidades 1,2-vinila. Essas unidades tornam o polímero mais rígido, provocando um aumento da $\mathrm{Tg}$. Neste trabalho, o valor máximo para o teor de unidades 1,2-vinila foi de 1,1\%, que não é suficiente para aumentar o valor da $\mathrm{Tg}$.

\section{Conclusões}

No estudo sobre o efeito da adição de THF ao solvente da polimerização, o teor de THF que teve maior influência sobre as propriedades do polímero foi $200 \mathrm{ppm}$. Quando foram adicionados $200 \mathrm{ppm}$ de THF simultaneamente ao solvente do preparo do catalisador e ao solvente da polimerização, o efeito deletério do THF foi ainda mais acentuado.

Quando se adicionou $1 \mathrm{ppm}$ de TMEDA ao solvente da polimerização, já ocorreu uma queda significativa no rendimento da polimerização e na massa molar, a polidispersão aumentou ligeiramente e a estereoespecificidade catalítica praticamente não variou. Quando se adicionou simultaneamente $1 \mathrm{ppm}$ de TMEDA ao solvente do preparo do catalisador e ao solvente da polimerização o efeito do TMEDA foi mais acentuado.

O TMEDA ao ser adicionado ao solvente da polimerização interfere mais acentuadamente nas características da polimerização, quando comparado ao efeito do THF. Este fato pode ser comprovado ao se observar os valores de rendimento obtidos. A adição de $15 \mathrm{ppm}$ de TMEDA ao solvente da polimerização, produziu um rendimento de 5 gramas de polímero, contudo, mesmo com a adição de 200 ppm de THF, foram obtidos 17 gramas de polímero.
Quando o solvente utilizado no preparo do catalisador for proveniente de um solvente recuperado de um processo de polimerização aniônica, este deve conter menos de 200 ppm de THF e menos de $1 \mathrm{ppm}$ de TMEDA, caso contrário as características desejadas para o polímero não serão alcançadas. A temperatura de transição vítrea ( $\mathrm{Tg}$ ) não foi afetada pela adição de doadores de elétrons, comportamento esperado, tendo em vista que o teor de unidades 1,2-vinila.

\section{Agradecimentos}

Os autores agradecem à UERJ, à FAPERJ (Bolsa Cientista de Nosso Estado), ao CNPq (Adicional de Bancada) e à Petroflex Indústria e Comércio pelo apoio financeiro.

\section{Referências Bibliográficas}

1. International Institute of Synthetic Rubber Producers; " Worldwide Rubber Statistics", Houston, (1999).

2. "Novos elastômeros para os segmentos de pneus e bandas", Borracha Atual, v. 39, p. 40-43, mar./abril (2002).

3. Lauretti, E.; Miani, B. \& Mistrali, F. - Rubber World, p. 3437, maio (1994).

4. Porri, L.; Ricci, G. \& Shubin, N. - Macromolecules Symp., v. 128, p. 53-61 (1998).

5. Rocha, T.C.J.; Coutinho, F. M. B.; Costa, M. A. S.; Nunes, D. S. S. \& Soares, B. G. - "Efeito de doadores de elétrons na polimerização de butadieno com catalisadores Ziegler-Natta à Base de Neodímio", in: Anais do $7^{\circ}$ Congresso Brasileiro de Polímeros, p. 868-869, Belo Horizonte - MG, nov (2003).

6. Tornqvist, E. G. M. - "The historical background of syntethic elastomers with particular emphasis on the early period", in: High Polymers: Polymer Chemistry of Synthetic Elastomers, parte 1, p. 21-94, Kennedy, J. P., Tornqvist, E. G. M., John Wiley \& Sons, New York (1968).

7. Cooper, W.; Eaves, D. E.; Vaughan, G.; Degler, G. \& Hank, R.- "Electron Donors in Diene Polymerization", in: Elastomer Stereospecific Polymerization, Library of Congress Catalog Card, 66-15861, p. 46-65. Americal Chemical Socity, New York (1966).

8. Porri, L.; Ricci, G.; Giarrusso, A.; Shubin, N. \& Lu, Z. - "Recent developments in lanthanide catalyst for 1,3-diene polymerization", in: Olefin Polymerization, cap. 2, p. 1530, Americal Chemical Socity, Washington (2000).

9. Yang, J.; Tsutsui, M.; Chen, Z. \& Bergbreiter, D. E. Macromolecules, 15, p. 230-233 (1982).

10. Fraga, L. A.; Tavares, M. I. B.; Coutinho, F. M. B.; Costa, M. A. S. \& Santa Maria, L. C. - Polímeros: Ciência e Tecnologia, 13, no 4, p. 229-234 (2003).

11. Furukawa, J. - Journal of Pure and Applied Chemistry, 42, p. 495-508 (1975).

12. Porri, L.; Giarrusso, A. \& Ricci, G. - Polymer Science. Ser. A, 36, no 10, p. 1421-1432 (1994).

Enviado: 26/08/04

Reenviado: $22 / 11 / 04$

Aprovado: 25/11/04 